\title{
Acute ST-segment elevation myocardial infarction after amoxycillin-induced anaphylactic shock in a young adult with normal coronary arteries: a case report Aristofanis Gikas*1, George Lazaros ${ }^{2}$ and Kalliopi Kontou-Fili ${ }^{3}$
}

\author{
Address: ${ }^{1}$ Health Center of Salamis, Salamis, Greece, ${ }^{2}$ Cardiology Department, 'Elpis' General Hospital of Athens, Athens, Greece and ${ }^{3}$ Department \\ of Allergology and Clinical Immunology, 'Laiko' General Hospital of Athens, Athens, Greece \\ Email: Aristofanis Gikas* - argikas@internet.gr; George Lazaros - glaz35@hotmail.com; Kalliopi Kontou-Fili - kontoufk@otenet.gr \\ * Corresponding author
}

Published: 25 February 2005

BMC Cardiovascular Disorders 2005, 5:6 doi:10.1 186/147I-226I-5-6

This article is available from: http://www.biomedcentral.com/|47|-226|/5/6

(c) 2005 Gikas et al; licensee BioMed Central Ltd.

This is an Open Access article distributed under the terms of the Creative Commons Attribution License (http://creativecommons.org/licenses/by/2.0), which permits unrestricted use, distribution, and reproduction in any medium, provided the original work is properly cited.

\begin{abstract}
Background: Acute myocardial infarction (MI) following anaphylaxis is rare, especially in subjects with normal coronary arteries. The exact pathogenetic mechanism of $\mathrm{Ml}$ in anaphylaxis remains unclear.

Case presentation: The case of a 32-year-old asthmatic male with systemic anaphylaxis, due to oral intake of $500 \mathrm{mg}$ amoxycillin, complicated by acute ST-elevation MI is the subject of this report. Following admission to the local Health Center and almost simultaneously with the second dose of subcutaneous epinephrine $(0.2 \mathrm{mg})$, the patient developed acute myocardial injury. Coronary arteriography, performed before discharge, showed no evidence of obstructive coronary artery disease. In vivo allergological evaluation disclosed strong sensitivity to amoxycillin and the minor (allergenic) determinants of penicillin.

Conclusion: Acute ST-elevation MI is a rare but potential complication of anaphylactic reactions, even in young adults with normal coronary arteries. Coronary artery spasm appears to be the main causative mechanism of $\mathrm{MI}$ in the setting of "cardiac anaphylaxis". However, on top of the vasoactive reaction, a thrombotic occlusion, induced by mast cell-derived mediators and facilitated by prolonged hypotension, cannot be excluded as a possible contributory factor.
\end{abstract}

\section{Background}

Acute myocardial infarction (MI) complicating anaphylaxis induced by drugs or other chemicals is uncommon and only sporadic cases have been reported [1-9]. The underlying pathogenetic mechanisms have not been fully elucidated. The case of a 32-year-old man with normal coronary arteries, who developed acute MI following amoxycillin-induced anaphylaxis, is the subject of this report. The underlying pathogenetic mechanisms are also discussed and the relative literature is reviewed.

\section{Case presentation}

A 32-year-old man was admitted to the emergency room of the local Health Center because of anaphylaxis, which developed 2 hours and 15 minutes after the ingestion of amoxycillin (500 mg), prescribed by his dentist. Prodromal signs of anaphylaxis (flushing, pruritus, warmth, urticaria) reportedly occurred about 15 minutes before the onset of symptoms from other systems. Ten days earlier the patient, an asthmatic since childhood, had completed a 4-day course of amoxycillin (500 mg TID) without any 

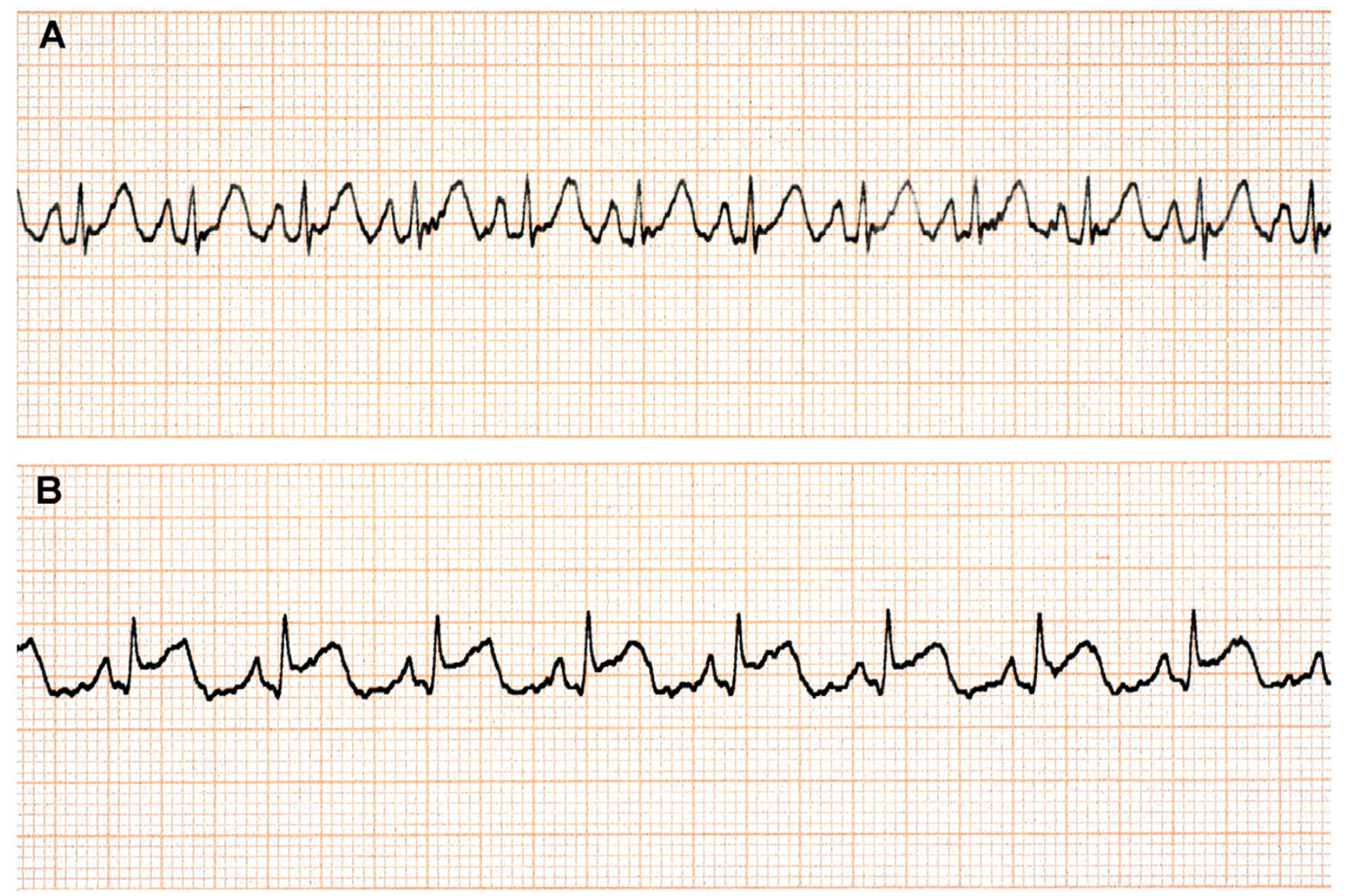

Figure I

Lead II monitor strip recorded shortly after admission (A) and at the chest pain onset (B).

side effects. Apart from obesity, there were no other risk factors for coronary artery disease.

On admission the patient was in acute distress. He was complaining of dizziness, blurred vision, dyspnea and abdominal pain. Initial examination revealed an obese man $\left(\right.$ Weight $=130 \mathrm{~kg}$, Body Mass Index $=38 \mathrm{~kg} / \mathrm{m}^{2}$ ) with generalized erythema, angioedema, cyanosis and diffuse wheezing; the systolic blood pressure was $70 \mathrm{mmHg}$ and the pulse rate $120 \mathrm{bpm}$. The patient was then connected to a cardiac monitor, which showed sinus tachycardia (approximately $140 \mathrm{bpm}$ ) without ST-segment and T wave abnormalities (Fig. 1A). Pulse oxymetry demonstrated an oxygen saturation $\left(\mathrm{SpO}_{2}\right)$ of $90 \%$.

Epinephrine $(0.3 \mathrm{mg}$ or $0.3 \mathrm{ml}$ of a dilution $1: 1000)$ was injected subcutaneously (SC); dimethindene (4 mg) and hydrocortizone $(500 \mathrm{mg}$ ) were administered intravenously (IV) in slow infusion. Nebulized salbutamol and supplemental oxygen were given as well. Normal saline with $50 \mathrm{mg}$ ranitidine hydrochloride and Ringer's solution were infused through separate intravenous lines.

Due to unsatisfactory clinical response (persistence of hypotension and tachycardia, despite improvement of the pulmonary signs) a second dose of epinephrine (0.2 $\mathrm{mg}$ ) was given SC 20 minutes later. Almost simultaneously with the administration of the second dose of epinephrine, ST-segment elevation appeared on the monitor (Fig. 1B) and the patient complained of substernal chest pain. A 12-lead electrocardiogram (ECG) showed ST segment elevation in leads II, III, aVF, and $\mathrm{V}_{3}$ to $\mathrm{V}_{6}$ (Fig. 2). A single dose of $325 \mathrm{mg}$ acetylsalicylic acid was given per os; heparin (5000 UI) and pethidine hydrochloride (25 mg) were administered IV. An hour later the patient was hemodynamically stable. The arterial blood pressure was $125 /$ $90 \mathrm{mmHg}$ and $\mathrm{SpO} 2$ rose to $96 \%$. However, the chest pain persisted and nitroglycerin titrated at a dose of $25 \mu \mathrm{g} /$ min was infused IV, without complete symptom relief. At 

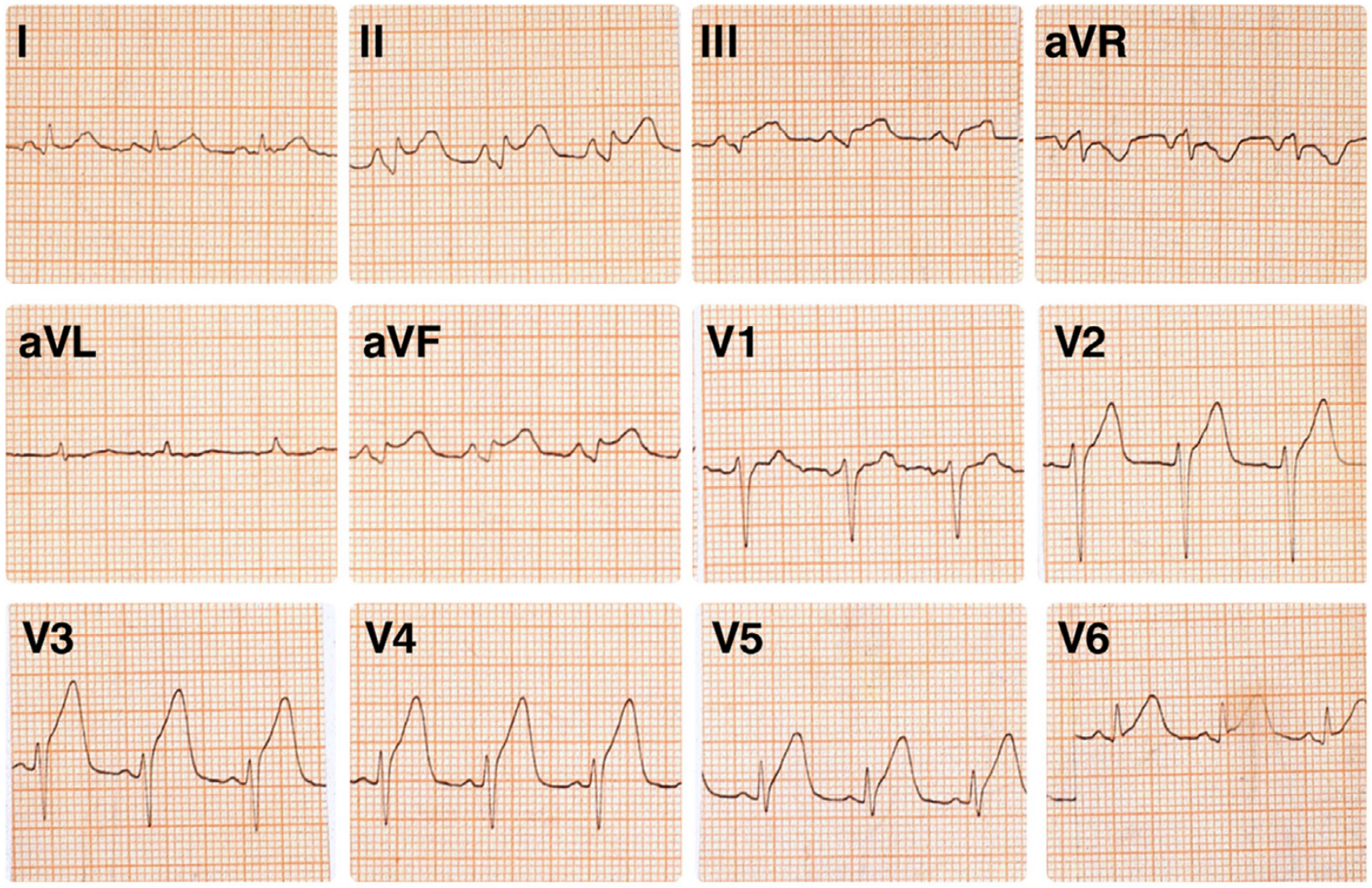

\section{Figure 2}

ECG recorded during chest pain.

this point the patient was transferred to the Coronary Care Unit (CCU) of the nearest general hospital.

Treatment in the CCU included thrombolysis with reteplase - administered according to the standard protocol -2 hours after the onset of chest discomfort, which according to the established clinical and electrocardiographic criteria was considered successful [10]. The peak levels of serum troponin I and creatine phosphokinase were $45.5 \mathrm{ng} / \mathrm{ml}$ (normal $=0-2 \mathrm{ng} / \mathrm{ml}$ ) and $575 \mathrm{U} / \mathrm{L}$ (nor$\mathrm{mal}=25-195 \mathrm{U} / \mathrm{L})$, respectively; while the MB fraction was $77 \mathrm{U} / \mathrm{L}$ (normal $=0-24 \mathrm{U} / \mathrm{L}$ ). The rest of the laboratory results, including serum cholesterol, LDL, HDL, Lpa and triglycerides, were within normal limits. An ECG performed before discharge showed complete loss of potentials in leads III and aVF and partial loss of potentials with a small q wave in lead II (Fig. 3). An echocardiographic study performed on the $5^{\text {th }}$ hospital day showed preserved systolic function (ejection fraction $60 \%$ ) without wall motion abnormalities. Left (Fig. 4) and right (Fig. 5) cor- onary angiography showed no evidence of obstructive coronary artery disease; left ventriculography was normal as well. The patient recovered completely and was discharged a week after admission. He was referred to the adult Allergology Center of our area performing diagnostic work up for drug allergy.

Prick skin tests (PST) were performed using penicilloyl polylysine (PPL), and minor determinant mixute (MDM) [supplied as Allergopen by Allergopharma (Reinbeck, Germany)]; amoxycillin, ampicillin and cefamandole solutions were also used (concentration $20 \mathrm{mg} / \mathrm{ml}$ ) for PST. PST were strongly positive [ $4+$ reaction (on a scale of $1-4)$ i.e. wheal $>5 \mathrm{~mm}$ in diameter with pseudopodes, with no reaction at all to the diluent control] to amoxycillin and ampicillin. Intradermal tests were performed only to PPL, MDM (dilution 1/10) and cefamandole $(0.2 \mathrm{mg} /$ $\mathrm{ml}$ and $2 \mathrm{mg} / \mathrm{ml}$ ) and resulted in strongly positive reaction (4+) only to the MDM. Circulating specific IgE to penicillin $V$, penicillin $G$, amoxycillin, ampicillin and 


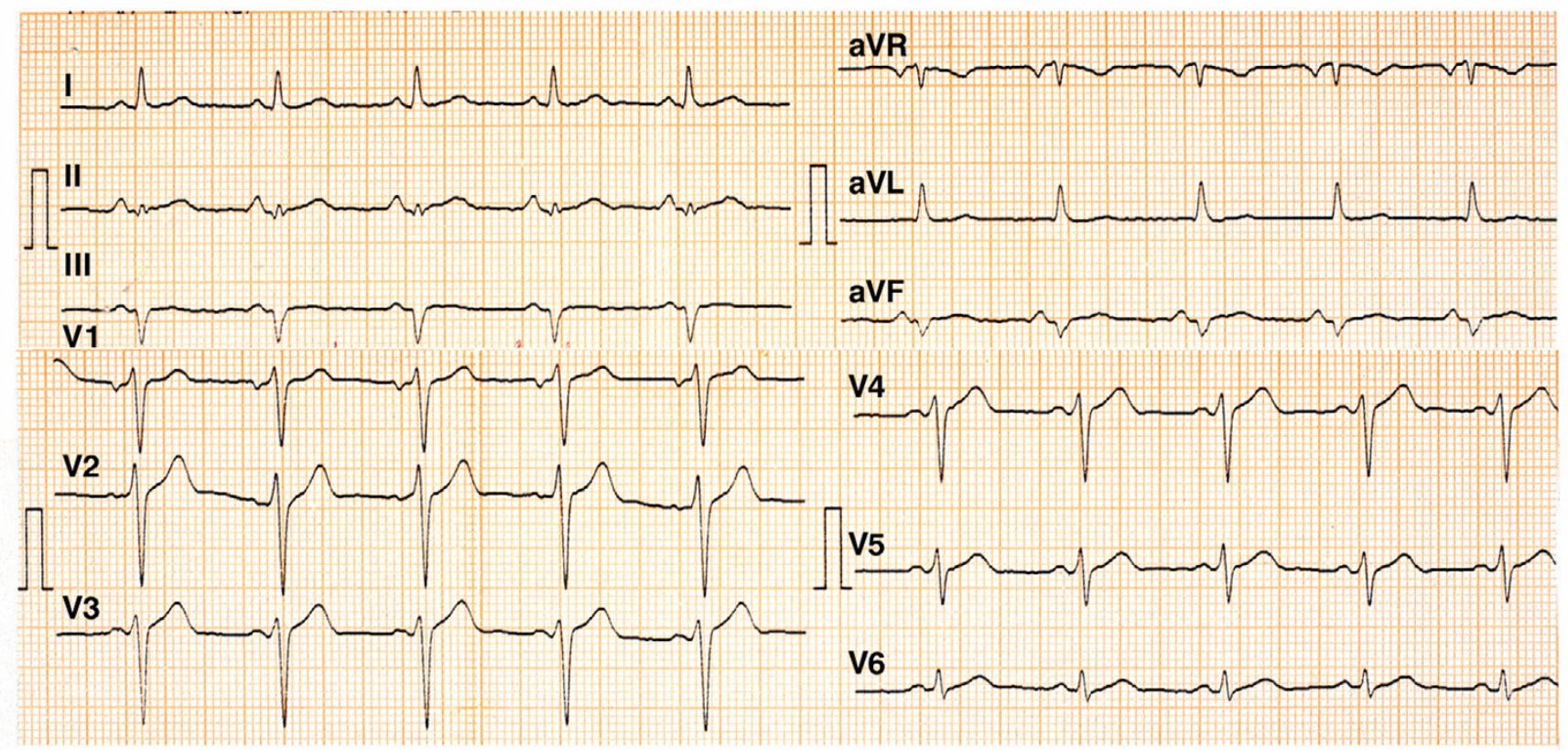

Figure 3

ECG recorded on hospital day $4^{\text {th }}$.

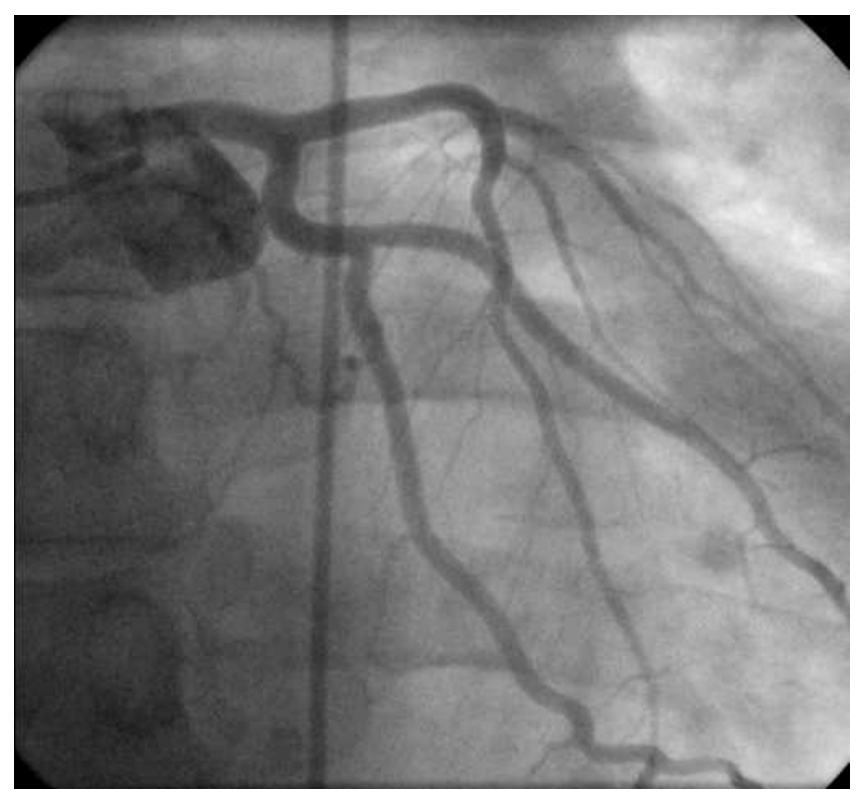

Figure 4

Left coronary angiogram. cefaclor was not demonstrable by CAP (Pharmacia, Sweden).

\section{Discussion}

Anaphylactic reactions may trigger cardiovascular events, including MI [1-9], primarily in subjects with underlying ischemic heart disease $[1,2,4,7,9]$ and rarely in individuals with normal coronary arteries $[3,5,6,8]$. Cardiovascular complications in the setting of anaphylaxis rarely occur in subjects less than 35 years old [11].

Acute coronary syndromes following antibiotic-induced anaphylaxis is uncommon and only few cases have been reported so far $[1,4,12-14]$. To our knowledge, only one case of amoxycillin-induced anaphylaxis complicated with acute MI has been documented in a 62-year-old man with underlying coronary artery disease [4].

Evidence that the human heart is the target as well as the site of anaphylaxis is constantly growing. A number of studies by Marone et al $[15,16]$ and others [17] have demonstrated mast cells within the human heart; they are strategically located perivascularly, in close proximity to myocytes, in the arterial intima and the shoulder region of atheromas. Cardiac mast cells express on their surface 


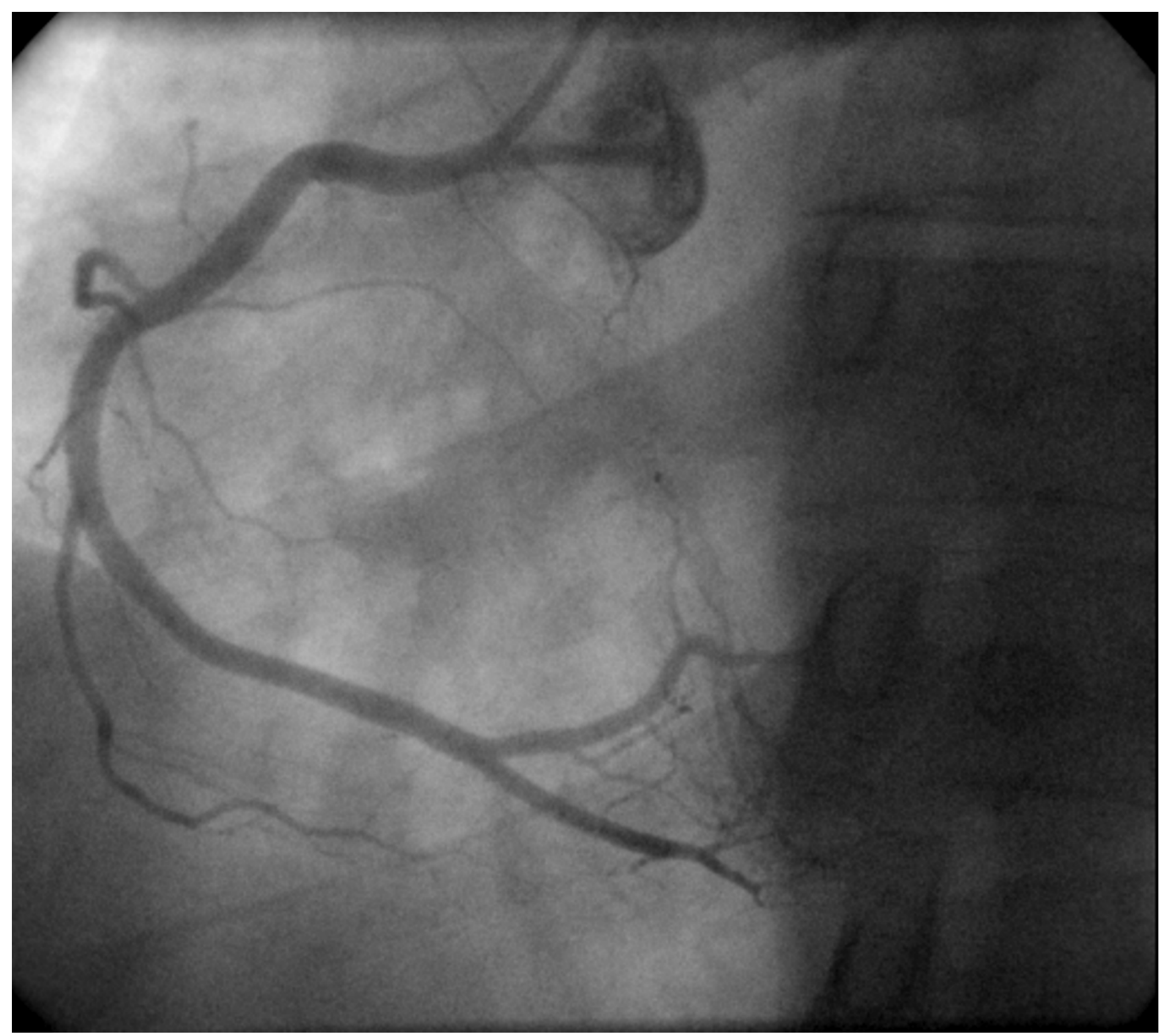

Figure 5

Right coronary angiogram.

high affinity receptors for IgE (FceRI) and also C5a receptors [18]. Mast cells activation through immunological and non-specific (non-immunological) stimuli leads to the release of a variety of vasoactive and pro-inflammatory mediators, preformed or de novo synthesized (histamine, prostaglandins, leukotrienes, enzymes, cytokines and others) $[15,19]$. Coronary spasm, which is proposed as the main underlying mechanism of allergy-induced coronary syndromes $[5,11,13,14,20,21]$, can be caused, directly or indirectly, by potent vasoactive mast cellderived mediators such as histamine, prostaglandin D2, thromboxane, cysteinyl leukotrienes $[15,18,22-24]$. In addition, mast cells are likely to affect coagulation and fibrinolysis at different levels through enzymes and mediators they secrete [15]. Therefore, mediators from perivascular and interstitial cardiac mast cells - as well as those reaching the heart from the pulmonary circulation - 
might affect coagulation, favoring platelet aggregation and thrombus formation $[15,25]$.

In the present case, the temporal sequence of events suggests that cardiac anaphylaxis was the triggering factor of MI. We propose that prolonged coronary vasospasm induced by vasoactive and inflammatory mediators, released during anaphylaxis, was the main causative mechanism. However, in view of the persistence of chest pain following IV nitroglycerin infusion, and its complete resolution promptly after IV thrombolysis, a thrombotic vascular occlusion, on top of the vasospastic reaction, cannot be excluded. The latter is also supported by the prolonged systemic hypotension, which, as it has been emphasized in previously reported cases [26], probably caused further reduction of the myocardial perfusion, thus, favoring in situ thrombus formation and subsequent coronary artery occlusion. In acute MI cases, presenting to centers with cardiac catheterization facilities, urgent coronary arteriography appears as the management strategy of choice for the final diagnosis. However, in the setting of acute anaphylaxis, this might not be the wisest choice, particularly in cases, like the present one, in which the offending allergen had been administered orally. Moreover, continuous or delayed allergen absorption could further aggravate anaphylaxis, and a late phase reaction represents a potential risk in all anaphylactic reactions. Finally, no bibliographical data are available concerning the tolerability of IV administered contrast agents in patients who have suffered a recent episode of severe systemic anaphylaxis.

The administration of epinephrine - a life saving agent in cases of anaphylaxis - has been implicated as a cause of acute $\mathrm{MI}$ in a limited number of reports $[27,28]$. In the present case, however, it appears unlikely that exogenous epinephrine was the initiating event for the following reasons: a) the first epinephrine dose ( $0.3 \mathrm{mg}$ ) was rather low to induce significant vasoconstriction in a subject with a body weight of $130 \mathrm{~kg}$, b) the mode of administration (SC) is considered the safest in this regard, c) the second dose $(0.2 \mathrm{mg})$, administered at a safe interval $(20 \mathrm{~min})$ after the first one, does not seem to be involved since its injection coincided with the onset of chest pain, before any anticipated drug absorption. On the contrary, in the above quoted cases $[27,28]$ the epinephrine-induced MI developed 5-15 minutes post injection. Moreover, the possibility of inadvertent intravenous administration of epinephrine appears improbable, since no blood was withdrawn in the syringe before drug injection. However, one might argue that the exogenous epinephrine could have aggravated a pre-existing coronary spasm, induced by mast cell-derived mediators. Hence, the precise effect of epinephrine in this clinical setting remains a matter of speculation.
The allergological evaluation performed in our patient showed strong sensitivity to amoxycillin and to the minor determinants, which are the allergenic epitopes associated with systemic anaphylaxis. The negative CAP results do not negate the in vivo findings, since it is well established that the in vitro techniques are not as sensitive as skin tests. Furthermore, CAP detects antibodies against the major determinants of penicillins (involved pathogenetically in penicillin-induced urticaria) and not to the minor ones, which are implicated in systemic anaphylaxis. For technical reasons, relating to both the Allergology Center and the patient's professional obligations as well as residence distance, the allergological work up was completed 6 months later; such a delay might also have contributed to the negative in vitro findings.

\section{Conclusion}

Acute ST-elevation MI is a rare but potential complication of anaphylactic reactions, even in young adults with normal coronary arteries. Physicians should be alert for such a complication in order to diagnose it early and treat properly.

It is fairly well established that that human heart can be both, the site and the target of severe anaphylaxis; in this setting cardiac mast cells - activated and releasing multiple vasoactive mediators - play an important role in pathogenesis of cardiac complications [16-18].

In the above case, mediator-induced coronary artery spasm was the main, but probably not the exclusive causative mechanism of anaphylaxis-related MI. The thrombotic vascular occlusion, induced by inflammatory mediators and facilitated by prolonged hypotension, cannot be excluded as a possible contributory factor.

\section{Abbreviations}

ECG = electrocardiogram; IV = intravenously; $\mathrm{MDM}=$ minor determinant mixute; $\mathrm{MI}=$ myocardial infarction; $\mathrm{NV}=$ normal values; $\mathrm{PPL}=$ penicilloyl polylysine; $\mathrm{PST}=$ prick skin tests; $\mathrm{SC}=$ subcutaneously.

\section{Competing interests}

The author(s) declare that they have no competing interests.

\section{Authors' contributions}

AG was responsible for the initial evaluation and management of the patient, GL was involved in the cardiological evaluation and management and, KK-F performed the allergological evaluation. All authors have equally contributed in the preparation and revision of the manuscript. All authors read and approved the final manuscript. 


\section{Acknowledgements}

We thank the physician K. Lidatakis and the nurses A. Koulouri and I. Lountzi for their contribution in the first-hour management of the patient and the documentation of the case. We thank the patient for giving us a written consent for publishing his case.

\section{References}

I. Quercia O, Rafanelli S, Emiliani F, Stefanini GF: Anaphylactic reaction to cinoxacin: report of one case associated with inferior acute myocardial infarction. Allerg Immunol (Paris) 2003, 35:6I-3.

2. Moorthy SS, Laurent B, Pandya P, Fry V: Anaphylactoid reaction to etomidate: report of a case. J Clin Anesth 200I, I 3:582-4.

3. Maillier B, Chapoutot L, Metz D, Bailly L, Reksa A, Sal R, Elaerts J, Bajolet A: Anaphylactic shock complicated by myocardial infarction: side effects of glaphenine? Ann Cardio Angeiol (Paris) 1992, 4 I:433-5.

4. Fernandez JS, Lado MP, Gonzalez NV, Rico MRL, Pardavila EA, Beiras AC: Acute myocardial infarction after amoxicillin-related anaphylactic reaction. Rev Esp Cardiol 1999, 52:622-4.

5. Cistero A, Urias S, Guindo J, Garcia-Moll M, Geli A, Bayes de Luna A: Coronary artery spasm and acute myocardial infarction in naproxen-associated anaphylactic reaction. Allergy 1992, 47:576-8.

6. Wagdi P, Mehan VK, Burgi H, Salzmann C: Acute myocardial infarction after wasp stings in a patient with normal coronary arteries. Am Heart J 1994, I 28:820-3.

7. Lopez-Minguez JR, Fernandez RG, Nunez VM, Herrera AM, Gomez JCA, Garcia-Andoain JM: Acute myocardial infarction secondary to anaphylactic reaction following shellfish ingestion. The need for rescue coronary angioplasty. Rev Esp Cardiol 2000, 53:1663-6.

8. Salam AM, Albinali HA, Gehani AA, Suwaidi JA: Acute myocardial infarction in a professional diver after jellysh sting. Mayo Clin Proc 2003, 78: I 557-60.

9. Vaswani SK, Plack RH, Norman PS: Acute severe urticaria and angioedema leading to myocardial infarction. Ann Allergy Asthma Immunol 1996, 77:101-4.

10. Cura FA, Roffi M, Pasca N, Wolski KE, Lincoff AM, Topol EJ, Lauer MS, Global Use of Strategies to Open Occluded Arteries V investigators: ST-segment resolution 60 minutes after combination treatment of abciximab with reteplase or reteplase alone for acute myocardial infarction (30-day mortality results from the resolution of ST-segment after reperfusion therapy substudy). Am J Cardiol 2004, 94:859-63.

II. Gupta KM, Gupta P, Rezai F: Histamine - Can it cause an acute coronary event? Clin Cardiol 200I, 24:258-9.

12. Rich MW: Myocardial injury caused by an anaphylactic reaction to ampicillin/sulbactam in a patient with normal coronary arteries. Tex Heart Inst J 1998, 25: I94-7.

13. Moreno-Ancillo A, Dominguez-Noche C, Gil-Abrados AC, Cosmes Martn PM: Acute coronary syndrome due to amoxicillin allergy. Allergy 2004, 59:466-7.

14. Lopez-Abad R, Rodriguez F, Garcia-Abujeta JL, Martin-Gil D, Jerez J: Myocardial ischemia due to severe amoxicillin allergy. J Investig Allergol Clin Immunol 2004, I 4: I62-4.

15. Marone G, De Crescenzo G, Patella V, Granata F, Verga L, Arbustini E, Genovese A: Human heart mast cells: Immunological characterization in situ and in vitro. In Mast cells and basophils Ist edition. Edited by: Marone G, Lichtenstein LM, Galli SJ . London, Pa: Academic Press; 2000:455-77.

16. Marone G, Bova M, Detoraki A, Onorati AM, Rossi FW, Spadaro G: The human heart as a shock organ in anaphylaxis. Novartis Found Symp 2004, 257: I33-49.

17. Kovanen PT, Kaartinen M, Paavonen $\mathrm{T}$ : Infiltrates of activated mast cells at the site of coronary atheromatous erosion or rupture in myocardial infarction. Circulation 1995, 92: 1084-8.

18. Marone G, De Crescenzo G, Patella V, Genovese A: Human cardiac mast cells and their role in severe allergic reactions. In Asthma and Allergic Diseases. Physiology, immunopharmacology and treatment Edited by: Marone G, Austen KF, Holgate S, Kay AB, Lichtenstein LM. Cambridge, Pa: Academic Press; 1998:237-57.

19. Patellla V, Marino I, Lamparter B, Arbustini E, Adt M, Marone G: Human heart mast cells. Isolation, purification, ultrastructure, and immunologic characterization. I Immunol 1995, I 54:2855-65.
20. Mori E, Ikeda H, Ueno T, Kai H, Maramaki N, Hashino T, Ichiki K, Katoh A, Eguchi A, Ueyama T, Imaizumi T: Vasospastic angina induced by non- steroidal anti-inflammatory drugs. Clin Cardiol 1997, 20:656-8.

21. Vincent GM, Anderson JL, Marshall HW: Coronary spasm producing coronary thrombosis and myocardial infarction. $N \mathrm{Engl} J$ Med 1983, 309:220-3.

22. Vigorito C, Giordano A, De Caprio L, Vitale DF, Maurea N, Silvestri P, Tuccillo B, Ferrara N, Marone G, Rengo F: Effects of histamine on coronary hemaodynamics in humans: role of $\mathrm{HI}$ and $\mathbf{H 2}$ receptors. J Am Coll Cardiol 1987, I 0:1207-I3.

23. Ginsburg R, Bristow MR, Kantrowitz N, Baim DS, Harrison DC: Histamine provocation of clinical coronary artery spasm: implications concerning pathogenesis of variant angina pectoris. Am Heart ] 1981, 1 02:819-22.

24. Vigorito C, Giordano A, Cirillo R, Genovese A, Rengo F, Marone G: Metabolic and hemodynamic effects of peptide leukotriene C4 and D4 in man. Int J Clin Lab Res 1997, 27: I78-84.

25. Laine P, Kaartinen M, Penttila A, Panula P, Paavonen T, Kovanen PT: Association between myocardial infarction and the mast cells in the adventicia of the infarct-related coronary artery. Circulation 1999, 99:361-9.

26. Massing JL, Bentz MH, Schlesser P, Dumitru C, Louis JP: Myocardial infarction following a bee sting. Case report and review of the literature. Ann Cardio Angeiol 1997, 46:3 I I-5.

27. Ferry DR, Henry RL, Kern MJ: Epinephrine-induced myocardial infarction in a patient with angiographically normal coronary arteries. Am Heart J 1986, I I I: I | 93-5.

28. Saff R, Nahhas A, Fink JN: Myocardial infarction induced by coronary vasospasm after self-administration of epinephrine. Ann Allergy 1993, 70:396-8.

\section{Pre-publication history}

The pre-publication history for this paper can be accessed here:

http://www.biomedcentral.com/1471-2261/5/6/prepub
Publish with Biomed Central and every scientist can read your work free of charge

"BioMed Central will be the most significant development for disseminating the results of biomedical research in our lifetime. "

Sir Paul Nurse, Cancer Research UK

Your research papers will be:

- available free of charge to the entire biomedical community

- peer reviewed and published immediately upon acceptance

- cited in PubMed and archived on PubMed Central

- yours - you keep the copyright

Submit your manuscript here:

http://www.biomedcentral.com/info/publishing_adv.asp
BioMedcentral 